\title{
Mobile Services in Oman: A Feedback on SMS-Parking Service
}

\author{
Syed Jafar Naqvi, Hafedh AIShihi, and Saqib Ali \\ Sultan Qaboos University, Al-Khod, Sultanate of Oman
}

cce3249@squ.edu.om hafedh@squ.edu.om saqib@squ.edu.om

\begin{abstract}
Mobile technology has evolved quite rapidly over the past few years. Many experts argue that the future computer technology rests in mobile or wireless computing. As the number of mobile phone users is increasing worldwide, different organizations are offering their services using these mobile devices

Oman is a developing country that strives to adapt M-services. The emerging mobile technology is impacting and becoming the main element that moves Oman forward and helps in its national development process. Internet penetration in most developing countries like Oman is still low as opposed to mobile dissemination. Despite the government plans and strategies to enhance internet diffusion, Internet subscribers comprise about $2.5 \%$ of the general population of Oman. In contrast, the number of mobile phones holders increased substantially since the launch of these services in 1996. Prepaid mobile services and SMS were introduced in 2001 and both are currently popular with subscribers. Such fine appeal influenced many government organizations to go mobile with their services. This paper reviews the current m-government initiatives in Oman and the feedback of the users on the SMS-Parking Service, introduced recently by a joint venture of the Muscat Municipality and the Oman Mobile company offering mobile services to its citizens.

This study shows that in spite of all these initiatives still the users of mobile are cautiously adapting to M-services as reported on SMS-Parking System.
\end{abstract}

Keywords: Mobile technology, Mobile devices, M-Services, Short Message Services (SMS), SMS-Parking Service, Oman E-government

\section{Introduction}

Mobile devices are now becoming a part of our daily and business lives. Mobile devices have changed how people interact and conduct business, driving demand for the next generation of products and services (ESCWA, 2007). With an estimated one trillion networked devices coming into play over the next five years, enterprises are increasingly looking to advances in wireless technology and mobile devices to grow revenues, reduce costs, maintain their competitive edge

Material published as part of this publication, either on-line or in print, is copyrighted by the Informing Science Institute. Permission to make digital or paper copy of part or all of these works for personal or classroom use is granted without fee provided that the copies are not made or distributed for profit or commercial advantage AND that copies 1) bear this notice in full and 2) give the full citation on the first page. It is permissible to abstract these works so long as credit is given. To copy in all other cases or to republish or to post on a server or to redistribute to lists requires specific permission and payment of a fee. Contact Publisher@InformingScience.org to request redistribution permission. and achieve high performance. (AMOS, 2010)

Mobile technology with the introduction of internet enabled mobile phones, PDA's, WiFi and wireless networks have offered their users to enjoy all the benefits of telephones, information accessing, and text messaging such as SMS. At the end of 2001, approximately $14 \%$ of the world population - $(850$ Mil- 
lion people) - was mobile phone users. This growth has been spectacular especially in Europe after the telecom industry de-regulation and adoption of Global System for Mobile (GSM) communications (Sadeh, 2002). Now, mobile phones are no longer used only for voice communication but are a convenient way of connecting to the Internet and are used for transferring data, mailing, and doing small scale business transactions (Sadeh 2002). Mobile phone penetration is well above the home PCs usage in Europe and it seems that the trend will continue (Varshney, 2000). The internet access via mobiles or wireless devices in Middle East has risen from $33.5 \%$ in 2007 to $40 \%$ in 2009 . Furthermore, the percentage of desktops use decreased from $63.50 \%$ to $58.93 \%$ as laptops use increased from $81.35 \%$ to $82.80 \%$ (Mobile net users on rise in Middle East, 2009). Mobile or wireless devices are widely used not only by developed countries but also commonly used by many other developing nations of the world including Oman.

Everyone is amazed at the quick proliferation of mobile phones in the developing world (Wayan, 2010). A recent estimate indicated that over half of the Omani populations have mobile devices, while the mobile infrastructure in Oman is currently covering $95 \%$ of the country (Ministry of National Economy, 2007). Oman has just started to utilize mobile channels to offer M-services to its citizens and clients. Some of the examples are like; Muscat Municipality developed an SMSParking Services system which enables motorists to pay parking fees via SMS. Higher secondary school students can now retrieve their end of semester grades (via SMS) by messaging their student seat numbers to a phone number designated by the ministry of education. Similarly, many other organizations are offering M-services through SMS, messaging to clients to inform them about their different activities.

Although there are many other applications of Mobile Services in Oman, which are needed to be explored further and to see their influence on users. As there is no study conducted on the adoption of this service. The results of this study may pave way for further studies not only on this service but also the other M-services offered in the country.

Purpose of the study: An attempt is made to overview the current mobile services initiatives taken in Oman and report the users' initial feedback on the SMS-Parking Services recently introduced in the Central Business District (CBD) of Muscat the capital of Oman.

\section{Background to the Study}

The Sultanate of Oman is one of the Gulf Cooperation Council (GCC) country located on the south east of the Arabian Peninsula. Oman occupies an area of 309,500 square kilometers (Ministry of Information - Oman, 2008b). It shares borders with United Arab Emirates to the northwest, the Kingdom of Saudi Arabia to the west, the Republic of Yemen to the south and the Arabian Sea lies eastwards. Oman is divided into five regions i.e. Adh-Dakhliyah, Adh-Dhahirah, AlBatinah, Al-Wusta and Ash-Sharqiyah and four governorates i.e. Al Buraymi, Dhofar, Musandam and Muscat. The total adult literacy in Oman is $81 \%$ which is very high in the region and per capita income reaching to US\$ 9070. Oman's real renaissance began with the accession of His Majesty; Sultan Qaboos bin Said Al Said to the throne on 23 July 1970 (Ministry of Information Oman, 2008a). Oman's government system is monarchy (Ministry of Information - Oman, 2008a).

According to the latest estimates (Ministry of National Economy - Oman, 2007), in 2006 Oman had a population of 2.677 million people. However, nearly 693,000 residents, (25.9 per cent of the population), were expatriates. Oman's currency is the Rial which is about USA \$2.60 per unit OMR (Omani Rial). The country's main revenue comes from oil and natural gas. The country's economic status was substantially enhanced by rising oil prices. According to the Ministry of National Economy-Oman (April 2008), Oman's 2008 GDP reached about OMR 13,737 million, compared to OMR 104 million in 1970. 


\section{M-Applications Services}

There are two ways of SMS widely used in Mobile applications services; they are commonly known as the PUSH \& PULL Services (Adagunodo, Awodele, \& Idowu, 2009). A Push SMS application is one whereby a message is been sent from the application to the user and it is one way. In other words, it is the mobile application that initiates a message.

\section{Push Services}

Muscat Securities Market has developed a paid service that enables investors to receive regular updates on market and stock alerts via SMS. The service also enables users to get an SMS every 30 minutes on market movers -top winners, losers and most active companies (Oman Mobile, 2010).

The Civil Aviation and Meteorology in cooperation with Oman Mobile has introduced a weather forecast service for most cities and towns in Oman that allows users to receive weather reports on their mobiles.

Other public organizations have also started to send bulk messages to citizens informing them about certain activities and events. For example, the Public Authority for Social Insurance has currently begun a public campaign to publicize its services and benefits to clients. One of the methods used was to send announcements through SMS to all residents in Oman.

Another example is in Oman Tender Board and Ministry of Manpower where they now send notification messages to clients about their transactions and/or other different issues such as new tenders and job vacancies etc. (Oman Mobile, 2010).

\section{Pull Services}

A Pull SMS application on the other hand is one whereby a user sends a request and obtains a reply from the application, such as:

The Royal Oman Police (ROP) initiated a mobile service allowing drivers to inquire and receive information about their traffic offences. Motorists send a message, of their National ID card number and vehicle details to, '3004' and they receive information on the number of traffic offences and the fine to be paid. The ROP plans to enable the system to notify drivers of their offences as soon as they happen, which will be useful to parents to keep an eye on their children driving activities, and business owners can monitor their company's drivers violations on time which can help reduce the traffic offences (Naqvi \& Al-Shihi, 2009).

The Ministry of Education now sends the final General School Certificate (GSC) results to students via SMS. Alternatively, students can inquire about their results by messaging their seat numbers to '92020' and receive their final results. In addition, the Higher Education Admission Center now informs students on their enquiry of their admission status in different institutions via SMS, allowing them to accept or reject the offer by messaging back their choices. (Oman Mobile, 2010).

Muscat Municipality first time offered SMS-Parking Services which enables motorists to pay parking fees via SMS. This service is viewed and the users' feedback is reported in this paper. This new service SMS-Parking Service are offered along the traditional Parking service.

\section{Traditional Parking Services Overview}

The Parking in Muscat especially in Central Business District (CBD) is extremely difficult. The Muscat Municipality has designated parking areas for car parking services with sign boards' instructions. The car parking is allowed with the payment of the parking fee only through the pay- 
ment booths. The users can park the car in a designated area and look for the municipality parking payment booth. The user can pay the parking fee through coins for the time required and get a receipt. At present the charges are 50 Baisa for half an hour parking. The users can enter the coin either through 50 Baisa coins or 25 Baisa coins for the time required and get receipts in duplicate. One part of this receipt has to be displayed behind the wind shield of the car and the second one the user can keep with him for his/her record. The parking ticket is valid for the specified date and time as mentioned on the ticket. If the users wish to extend the period, he/she must go back to the booth and get another ticket and replace the old ticket with the new one which is inconvenient and time consuming. As the user has to look for coins and take care of the ticket and keep an eye on the expiry time as well. The penalty, for nonpayment of parking ticket on the expiry of the parking time, is 100 times more than the fee for half an hour parking.

The disadvantages of traditional Parking Services are summarized as: Disadvantages:

- Park the car and get the right coin/s

- The most machines do not accept the new coins of 50 Baisa

- Time consuming walk to the booth and then pay and walk again to the booth for renewal when needed.

- Keeping an eye on the expiry time and rush to the booth for renewal or move the car.

- If one booth is down the user has to search and use the other booth

\section{SMS-Parking Services}

The Muscat municipality and Oman mobile have introduced a new service as described earlier for paying the parking fee in Muscat business district. The service is simple to use, the users should have a mobile phone with either a pre or post paid option and the fee will be deducted or sent through a monthly mobile phone bill. The users can park the car and send an SMS to "90091" with the details of the car plate number and the minutes for which the parking is needed. The users will get a confirmation message for a successful transaction. The user will then get a reminder message five minutes before the allocated time expires either to move the vehicle or renew their parking time (Oman Mobile, 2010). This flow of information from the users goes to the Oman mobile and passes to the Muscat Municipality data bank. The inspector receives the information on his PDAs and then uses this information while inspecting the parking sites for violations. There are three steps to this service as shown in Figure 1.

$-1-$

SMS to 90091 your car no, car code, time in minutes. E.g.: 6416 HR 60
$-2$

A confirmation message will be received with ticket no, car no, car code, purchase date/time, expiry date/time
$-3-$ 5 minutes before time expires customer will be notified through SMS

Figure 1. Three steps of parking service

The major features of this service are summarized as:

- Users can pay the parking fee by sending a SMS.

- It functions 24 hours a day, 7 days a week.

- Users are notified when they make an invalid request.

- It is relatively easy to use.

- It is flexible and could be used form any mobile accessible location.

- It offers a paperless, efficient, quick and convenient service to the users.

- It saves time just park the car and send an SMS. 


\section{Feedback on using SMS-Parking Services}

An initial survey was conducted to explore the users' feedback on the SMS-Parking Service recently introduced in Muscat area of Oman. The data was collected between late 2009 and early 2010 from seventy eight car parking users, of which $56 \%$ were male and $44 \%$ female. A questionnaire was developed for this study consisted of fourteen questions. These questions were designed based on three major domains related to accessing SMS-Parking Services, attitudes towards the use of the service and the users' preferences SMS Parking over traditional parking system. Responses to each question were based on a scale of 1 to 5 , where $1=$ Strongly Disagree, 2 $=$ Disagree, 3 = Uncertain, $4=$ Agree, $5=$ Strongly Agree. The questionnaire was administered in the same way to all users. Only the questionnaires which were responded and filled up completely were taken into consideration.

Simple analysis of the data was done by computing the aggregate responses on the major domains using Microsoft Excel 2007 and the results were presented through plotting a graph to highlight the responses.

\section{Analysis of Results}

\section{SMS-Parking Services Accessibility}

The overall feedback on accessing the SMS-parking service by users indicated that $62 \%$ of the total 78 males and females respondents agree that SMS-Parking services are easily accessible from any location at any time through a mobile phone whenever the service is needed.

It was encouraging that more than half of the total number of users were able to access the service and pay from any location whenever the service is needed. Still a large number of respondents, either uncertain or disagree on the accessibility of this service. It appears that these users were either not aware of its advantages or they were reluctant to use the service.

\section{Attitudes toward SMS-Parking Services}

On the questions related to attitudes, the overall feedback on users attitudes toward the SMSparking service indicated that $51 \%$ of the total 78 males and females respondents had positive attitudes toward this service. Out of the total 78 users nearly half of them were having positive attitudes toward it and the remaining either did not bother to try to use this service or tried but did not have positive attitudes toward it.

\section{SMS-Parking Services and Users Preferences}

In the next set of questions on parking systems, the users were asked of their preferences. In response to the question: Do you prefer the SMS Parking service over Traditional system : 39 users agreed which comes to $50 \%$ that they prefer to use the new SMS Parking service. It showed that the users who had a positive attitudes indicated their preference in favor of the new SMS Parking service. But to a surprise a large number of users, nearly $50 \%$, still prefer to continue using the traditional service which probes to further investigation as shown in Figure 2.

These responses indicated that though many users prefer SMS Parking service over the traditional one yet there are quite a good number of users either they have not exposed themselves to the technology or feel difficulties in using it or have no awareness of its advantages and are very much unenthusiastic for a change. 


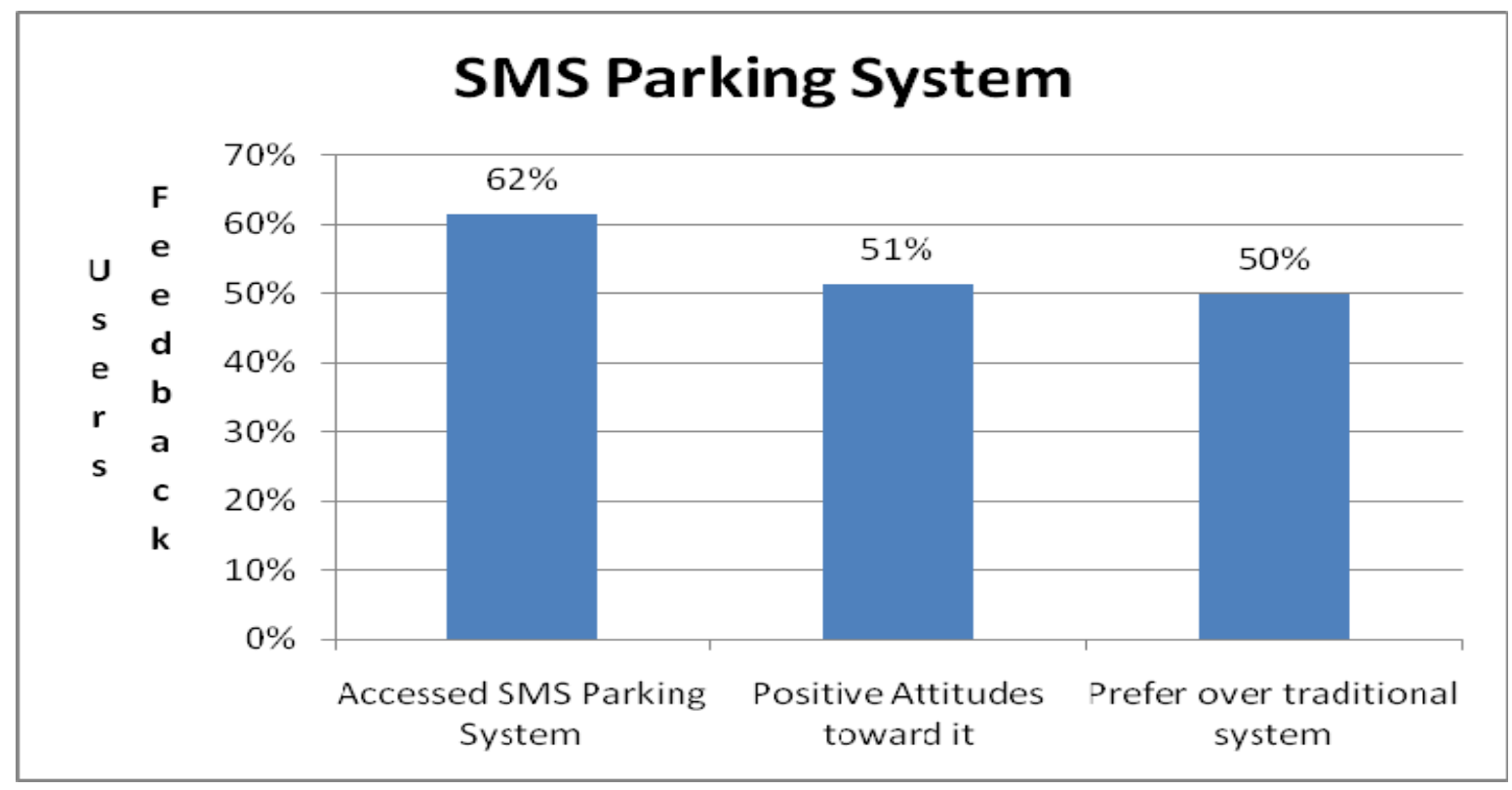

Figure 2. User responses

It appears that there is a need for creating greater awareness on the availability, accessing and advantages of this new service. As Muscat Municipality is the one offering this service can play a major role in this respect and may look for means to improve the service further.

\section{Summary and Conclusion}

Mobile technology with the introduction of internet has enabled mobile phone users to enjoy all the benefits of telephones, information accessing, and text messaging. The widespread use of wireless technology and mobile devices have made it possible for many enterprises to use them to grow revenue, reduce costs, maintain their competitive edge and achieve high performance. This advancement in mobile technologies has also influenced many government organizations to go mobile with their services.

Oman is a developing country and adapting to the new technologies. These technologies are impacting and becoming the main elements that help Oman to move forward in its national development process. Oman has just started to utilize mobile channels to offer M-services to its citizens and clients. Some of the examples are; Muscat Municipality which developed an SMSParking Services system that enables motorists to pay parking fees via SMS. Higher secondary school students can now retrieve their end of semester grades (via SMS) by messaging their student seat numbers to a phone number designated by the ministry of education, Muscat Securities Market sends updates on market and stocks alerts to investors via SMS. Similarly, many other organizations are offering M-services through SMS, messaging clients to inform them about their different activities.

Though many mobile services are introduced in Oman, there has been no study conducted on their success or failure. This paper is an attempt to report on the initial work done on the SMS Parking service, which is a joint venture of the Muscat Municipality and the Oman Mobile company offering mobile services to its citizens.

The results showed that more than half of the users were able to access and tried this new service. Still a large number of respondents either uncertain or disagree on the accessibility of this service. It appears that these users were either not aware of its advantages or they were reluctant to use the service. Moreover, only half of the total number of respondents indicated a positive attitude to- 
wards it, and similar number of users indicated their preference, for using the new service over the traditional one. Based on these results, this new service cannot be called a great success. This warrants further investigation with a larger sample size and a more robust analytical model.

However, some observations are made:

Reliable mobile infrastructure: The SMS-Parking Service as described above, the municipality inspectors use PDAs connected to the GPRS network to check if vehicles are legally parked. Obviously if the mobile network is temporary down, the SMS-parking system will be affected too. Moreover, such incident may cause faulty ticketing to legally parked vehicles, which could negatively influence users trust and satisfaction, and degrade the system image.

This could be lack of awareness and unfamiliarity with the procedure for using the service or technological difficulties such as un-availability of network or slow responses from the service provider which may also reduce the users' enthusiasm to try this new service. A reliable and efficient mobile infrastructure is a must for the success of any M-service initiative such as M-parking service.

Creating more awareness: Beside these technical difficulties, the users may not excited if there is a lack of awareness and unfamiliarity with the procedure for using this service. For a greater success, the municipality of Muscat should invest in marketing, educating and creating more aware-

ness on the availability of the service to consumers and what it offers and how it can be beneficial to them. This could be done by distributing brochures which describe to the users of the SMS-

Parking Service its offers such as: convenience, time saving and easy payment with other advantages.

Since there is always room for improvement to offer better services to clients, the service provider needs to explore the opportunities.

The results from this preliminary study provides a background for further study on this issue and pave way for new studies in other M-services offered in Oman.

The main limitations of the study are the sample size and robust analytical model. There is a need for further exploration on this study to see the impact of this newly introduced SMS Parking Service on its users. The outcome of this feedback may provide a background for further investigation and also other potential M-Services offered in the Sultanate of Oman and elsewhere.

\section{References}

Adagunodo, E. R., Awodele, O., \& Idowu, S. (2009). SMS user interface checking system. Issues in Informing Science and Information Technology, 6, 101-112. Retrieved from http://iisit.org/Vol6/IISITv6p101-112Adagunodo601.pdf

AMOS. (2010). Accenture mobility operated services. Retrieved August 8, 2010 from http://www.accenture.com/Global/Services/By_Industry/Communications/Services/AccentureMobility OperatedServices.htm

ESCWA. (2007). National profile for the information society in the Sultanate of Oman. New York: United Nations.

Ministry of National Economy - Oman. (2007). Statistical year book, Vol. 35.

Ministry of Information - Oman. (2008a). His Majesty Sultan Qaboos bin Said. Retrieved December 13, 2008 from http://www.omanet.om/english/history/sultan.asp?cat=hist

Ministry of Information - Oman. (2008b). Useful information. Retrieved December 13, 2008 from http://www.omanet.om/english/useful/basic.asp?cat=use

Ministry of National Economy - Oman. (2008). Monthly statistical bulletin, 19(4). 
Naqvi, S., \& Al-Shihi, H. (2009). M-Government initiatives in Oman. Issues in Informing Science and Information Technology, 6, 817-824. Retrieved from http://iisit.org/Vol6/IISITv6p817-824Naqvi678.pdf

Oman Mobile. (2010). Retrieved August 8, 2010 from http://www.omantel.net.om/OmanWebLib/Individual/Promotions/topup promotion.aspx?linkId=3

Sadeh, N. (2002). M-Commerce: Technologies, services, and business models. Hershey, PA: Wiley Computer Publishing.

Varshney, U., \& Vetter, R. (2000). Emerging mobile and wireless networks (Technology Information), Communications of the ACM, 43(6), 73-81.

Wayan, V. (2010). A New ICT4D Paradigm: Women + Mobile Phones $+m$ Services $=$ Economic Development. Technology salon, Washington D.C. Retrieved August 8, 2010 from http://www.technologysalon.org

\section{Biographies}

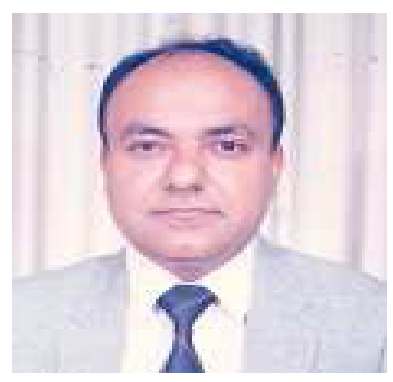

Dr. Syed J. Naqvi is an Assistant Professor in the Department of Information Systems, College of Commerce and Economics at Sultan Qaboos University. Prior to this he worked at many other prestigious universities and published widely on Computers and Information Systems education. His teaching interests include programming languages, Web applications development, e-commerce and computer networking with research interest in computer education.

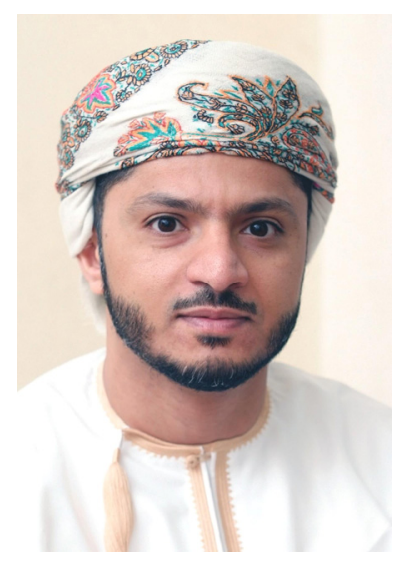

Dr. Hafedh AlShihi is an Assistant Professor at the College of Commerce and Eeconomics in Sultan Qaboos University. He has finished his $\mathrm{PhD}$ in e-Government at Victoria University in Melbourne, Australia in 2006, and his MSc in Computer and Information Systems at University of Detroit Mercy in Michigan, USA. He is a member of the Association of Information Systems (AIS) and the Special Interest Group on Electronic Government (SIGeGov). He is also a Research Associate in the Center for International Corporate Governance Research at Victoria University, Australia. He has several publications on egovernment adoption and dissemination and has attended several local and international conferences. He has been selected to be in the reviewing committee of several international conferences and journals such as the Journal of Information Technology for Development and the International We-B M-Government Services Initiatives in Oman 824 (Working for EBusiness) Conference in Australia. He has supervised several undergraduate, masters and $\mathrm{PhD}$ researches, several of which has been accepted in international conferences and received national and international recognition. Currently, he is teaching introductory and major Information Systems (IS) courses to undergraduate students and supervising the Information Systems Group at the Sultan Qaboos University (www.isg-zone.com). He writes a weekly article in popular local newspaper. 


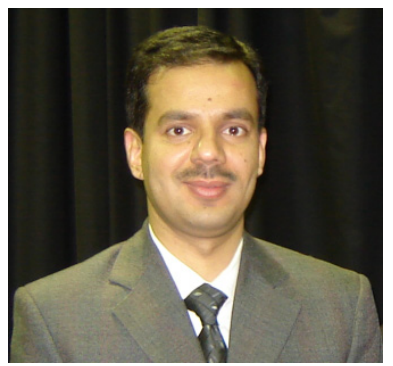

Dr. Saqib Ali is an assistant professor in the Department of Information Systems at Sultan Qaboos University, Muscat, Oman. He has also been active in teaching and research and development. He has published several peer-reviewed research papers and made significant contributions to the following numerous research areas: Business Process Modelling encompassing Business Rules, Modelling B2B Communication, Mobile Business Processes, Location Based Services, ContextAware Mobile Services, Component Based Development, ECommerce and Information Systems Security. Dr. Ali has been invited to serve in several international conference committees. He is a member of IEEE. 